\title{
What can a perception-memory expert tell a jury?
}

\author{
GEOFFREY R. LOFTUS \\ University of Washington, Seattle, Washington
}

\begin{abstract}
Witnesses to crimes and other forensically relevant events sometimes describe memories in which they express confidence that, on the basis of research in perception and memory, may be inappropriately high, given the circumstances of the case. The most effective way of conveying this observation and the reasons for it to a jury is via an expert in perception and memory. In any given case, a mosaic of factors having to do with perception and memory are relevant. I briefly sketch the most common of these factors and categorize them as to the degree to which they may be unambiguously and/or quantitatively applied to a specific case. I discuss one such factor, witness-object distance, in some detail, showing how an expert might describe distance effects on perception and providing examples from actual cases.
\end{abstract}

On August 23, 1995, in Newark, New Jersey, Errich Thomas was shot and killed during a robbery of his convenience store. As the killer fled the store, he was observed by a witness, Patricia McKinnis, from the porch of her home, $271 \mathrm{ft}$ away. Later, following a complex police investigation, Darrell Edwards was arrested for the crime. Despite the testimony of another eyewitness, Steven Blevins, who viewed the crime from close up and swore that the killer was not Mr. Edwards, Mr. Edwards was convicted on the basis of Ms. McKinnis's identification of him. Mr. Edwards has since languished in a prison cell, asserting his innocence, while his defense, now orchestrated by the New-York-based Innocence Project, winds through a labyrinthine appeals process.

Intuitively, Mr. Edwards's conviction seems wrongvery wrong. Even putting aside Mr. Blevins's favorable testimony, it appears obvious that Ms. McKinnis's distance from the killer, $271 \mathrm{ft}$, was too far for her to be able to see him clearly enough to be able to identify him. Why did the jury not realize this?

The reason, essentially, is that during the trial, there was no one to point out to the jury that a witness's perception of a person from that distance is extremely poor. What was emphasized to the jury, and what evidently underlay their verdict, was Ms. McKinnis's highly confident identification of Mr. Edwards, which evidently overrode any reservations they may have had about distance problems. Such a situation cries out for an expert, versed in the workings of human cognition, to provide information about (1) the perceptual consequences of seeing a person $271 \mathrm{ft}$ away and (2) the reliability of a high-confidence identification following such a view. The remainder of this article concerns the degree to which such an expert can assist a jury when issues of perception and memory form a signifi- cant part of a legal case. Although I will focus on criminal cases here, the issues that I will describe apply to both criminal and civil cases.

\section{"I'LL NEVER FORGET THAT FACE"}

A prosecutor's delight and a defense attorney's bane is an old cliché: the eyewitness who points to the defendant and utters some variant of "That's him! That's the person who I saw commit the crime! I'll never forget his face as long as I live!"

Both common sense and empirical evidence (e.g., Penrod \& Cutler, 1995) tell us that a confident, in-court identification of this sort is quite persuasive to a jury. Accordingly, a central issue discussed by an eyewitness expert is that, contrary to common sense, a confident witness need not be accurate. This issue is coming to the attention of judicial authorities, as exemplified by a 2001 memo from New Jersey Attorney General John Farmer to state law enforcement agencies, in which he emphasized the importance of guarding against identification procedures (most specifically, lineup and showup procedures) that may invest a witness with a false sense of confidence. Farmer noted that "studies have established that the confidence level that witnesses demonstrate regarding their identifications is the primary determinant of whether jurors accept identifications as accurate and reliable." This is certainly correct, and an eyewitness expert is in a position to alert jurors to situations that, on the basis of scientific studies, are known to lead to such a false sense of confidence.

It is not surprising that a confident witness sways jurors: In everyday life, high confidence usually is predictive of high accuracy. Therefore, it makes sense that a

G. R. Loftus, gloftus@u.washington.edu 
typical juror would use such predictive power as a default assumption in evaluating the credibility of a witness's identification. However, contrary to intuition, such predictive power can break down, and a great deal of scientific research has delineated the circumstances in which such a breakdown can occur. These circumstances include (1) an original event (e.g., seeing a person from a long way away, as in Mr. Edwards's case) that does not lend itself to a witness's being able to easily form an accurate memory of a criminal's appearance, along with (2) some form of suggestive postevent information that would bias the witness to reconstruct his or her memory in some fashion (e.g., identifying a suspect in a biased identification procedure). Under such circumstances, the witness is inclined to rehearse this reconstructed memory of the original event in such a way that the memory becomes strong and confidence inducing. Accordingly, although nonintuitively, the witness's confident identification of the suspect - now the defendant - at trial is based not, as the witness believes, on original information about the perpetrator's appearance acquired at the time of the crime, but on potentially inaccurate postevent information acquired at the time of the identification procedure.

Although this combination of circumstances is rare in most people's experience, it is not uncommon in crimes, accidents, and other forensically relevant events. Accordingly, the main purpose of a perception-memory expert is to describe to the jury when and why confidence should be not be taken as a predictor of accuracy. Concomitantly, the defense attorney's job is to demonstrate, often via hypothetical questions to the expert, that the facts of the case at hand mirror these circumstances (whereas the prosecutor often endeavors to show that they do not). This combination of information allows the jury to consider, in a reasonably informed and principled fashion, how to assess the in-trial confidence expressed by the witness.

\section{WHAT SPECIFICALLY CAN AN EYEWITNESS EXPERT TELL THE JURY?}

There are two sets of factors whose scientific underpinnings an eyewitness expert can describe to a jury: encoding factors and memory reconstruction factors.

\section{Encoding Factors}

Encoding factors determine a witness's ability to accurately encode important aspects of an event - commonly, although not always, some perpetrator's appearance. As is evident to any student of cognition, there are many such factors. The most common are the following.

\section{Lighting Conditions}

Many crimes and other legally relevant events occur at night. If lighting is poor, viewing is done using the scotopic visual system, which, unlike its photopic counterpart, is incapable of detecting colors or fine detail.

\section{Attention}

Because attention is a serial process, a witness often cannot attend to all the potentially relevant aspects of a scene during whatever limited time is available. Particularly, when the witness is also the victim of a crime, there are many relevant aspects of the scene-for example, potential danger, escape routes, degree of injury, and so on-that would be likely to commandeer attention (see, e.g., Steblay, 1992, for a discussion of the weapon focus effect). Given the failure of people to remember nonattended stimuli (e.g., Levin \& Simons, 1997), such fertile sources of attentional capture do not bode well for a witness's inclination to attend to and eventually remember things, such as the perpetrator's appearance, that will be more relevant later than immediately.

\section{Duration}

It is a matter of common sense - and is also true - that the longer the time during which a witness views a perpetrator, the greater the witness's opportunity to attend to and encode the perpetrator's appearance (e.g., Laughery, Alexander, \& Lane, 1971).

\section{Distance}

It is also a matter of common sense that a perpetrator who is close to a witness is easier for the witness to perceive and encode than is a perpetrator who is farther away. Recent research has allowed a quantification of information loss corresponding to a particular distance, as discussed more below.

\section{Cross-Racial Identification Factors}

Although something of an un-PC cliché, an extensive body of research has demonstrated that, in general, witnesses are more proficient at identifying members of their own race than at identifying members of other races (e.g., Meissner \& Brigham, 2001).

\section{Stress Levels}

Stress - particularly, high stress - is a challenging topic of scientific study, for obvious ethical reasons. Nonetheless, numerous studies have investigated the effects of high stress on mental functioning by using animals as subjects (e.g., Yerkes \& Dodson, 1908), by essentially ignoring ethical considerations (e.g., Berkun, Bialek, Kern, \&Yagi, 1962), or by studying individuals who voluntarily put themselves into highly stressful conditions (e.g., Artwohl, 2003). The conclusion based on this constellation of studies is that mental functioning of various kinds is impaired under conditions of high, as compared with moderate, stress.

\section{Alcohol Consumption}

Frequently, crimes are committed while witnesses are drunk. Significant alcohol consumption impairs visual perception-adding noise to the muscles that control the eyes, leading to both lack of focus and double vision_-diminishes 
transfer of information from short-term memory to longterm memory, and impairs visual adaption to darkness (e.g., Quintyn, Massy, Quillard, \& Brasseur, 1999).

\section{Memory Reconstruction Factors}

Beginning with Bartlett (1932) and accelerating since the mid-1970s, a considerable research effort has investigated memory reconstructive processes that operate during the interval between some event and the witness's recollection of it. This research has demonstrated memory changes in response to proffered postevent information ranging from addition of details to a scene (e.g., E. F. Loftus \& Palmer, 1974) to creation of entire events that never happened (e.g., E. F. Loftus, 2003). There are a number of potentially fertile sources of postevent information in legal cases, such as the following.

\section{Identification Procedures}

In most, although not all, criminal cases, a witness identifies a suspect prior to trial as the person that he or she saw commit the crime-which often becomes the prosecutor's prime evidence against the defendant. However, there are numerous ways in which identification procedures can be biased against the suspect (see, e.g., Wells \& Seelau, 1995).

Lineups. In a lineup (either a live lineup or a photo lineup), a suspect is shown amid some number of fillers - individuals known to have nothing to do with the crime. An unbiased lineup is one in which the suspect, if innocent, has no greater probability of being falsely identified than does any of the fillers. However, lineups can be biased in many ways. The most common are the following.

1. Physical bias. Either the suspect conforms more to the description originally provided by the witness, or the suspect stands out in some way (e.g., in a photo lineup, the picture of the suspect is larger, smaller, or tilted, or the suspect is differently clothed or shown against a different background, as compared with the fillers).

2. Unconscious transference. The suspect, in contrast to the fillers, can be shown to have had contact with the witness in circumstances other than the crime (e.g., they live in the same apartment complex, they went to school together, they buy methamphetamine from the same dealer, they attended the same Lifespring seminar). This allows the possibility that the witness's identification of the suspect was based on familiarity from such other encounters, rather than from seeing the suspect commit the crime.

3. Lack of double-blind procedures. The police officer administering the lineup knows who the suspect is, thereby allowing the officer to provide to the witness, either deliberately or inadvertently, information as to who the suspect is.

Showups. In a showup, a witness is shown a single suspect and asked to make a yes-no decision. ${ }^{1}$ Whereas a positive identification in a showup procedure probably depends, at least in part, on the match between the suspect's appearance and the witness's memory of the perpetrator, it is likely influenced also by other irrelevant biasing factors, including the witness's expectation that the suspect is the perpetrator, any pressure put on the witness to make a positive identification, or the witness's motivation to have someone arrested.

\section{Biased Interview Techniques}

Typically, a witness is interviewed many times about a crime that he or she witnessed, either in some official capacity or in the context of discussing the event with friends and neighbors. A common such situation is a sexual assault case in which the victim or a witness - often, a child - is interviewed about the behaviors of the defendant. There are many ways in which biasing information can be provided to the interviewee (e.g., Ceci \& Bruck, 1993). They include the following.

1. Suggestive/leading questions. Interviewers can, and often do, deliberately or inadvertently provide information to witnesses during the course of an interview. Thus, depending on whether the witness is initially interviewed by the prosecutor or by the defense attorney, the witness's memories can become biased toward one point of view or another.

2. Confirmation bias. The nature of biases that often accompany an interview has been explored within the context of confirmation bias - the tendency to seek or elicit information supporting one's preconceived position, instead of information that could disconfirm such a position. Within the context of interviews, an interviewersay, a prosecutor-would seek but would likely also provide information to the witness that would be consistent with the prosecution's case.

\section{Experiments}

Finally, specific experiments can be done that are designed to answer specific questions raised in a particular case. The following are two examples.

\section{Is a Photo Lineup Biased?}

Under some circumstances, it is reasonable to hypothesize that a lineup is biased. Such a putative bias can be assessed by carrying out an experiment in which the description of the suspect provided by the witness is read to subjects who are then shown the photo lineup and asked to identify the suspect. It can then be determined whether the subjects' probability of identifying the suspect is above chance.

\section{Visual Perception Under Specific Conditions}

Sometimes, a witness views the perpetrator of a crime under certain, reasonably well-specified conditions. In a recent case, for example, the witness viewed a gunman only by the light of a candle. In my laboratory, we asked subjects to look at a "perpetrator," similarly illuminated, for approximately $10 \mathrm{sec}$ and then to identify the "perpetrator" from a photo lineup. The noteworthy finding was that identification probability was at chance. 


\section{HOW USEFUL IS SUCH EXPERT TESTIMONY?}

In this section, I will attempt, somewhat subjectively, to assign psychological factors to categories defined by the specificity with which an experimental psychologist's description of them can be applied to a case at hand. I do not consider this categorization to be final; rather, I view it as a beginning of discussions about this topic. Space limitations allow a discussion only of encoding factors.

\section{Level 1 Effects}

Level 1 effects cannot be quantified, nor do they necessarily apply to all people. Descriptions of them are, however, helpful in providing a general picture of relevant cognitive issues. Examples are the effects of stress and cross-racial identification.

\section{Level 2 Effects}

Level 2 effects are those that cannot be quantified in a specific situation but apply to all people. Again, descriptions of them are useful insofar as they help provide a general picture of relevant cognitive issues. Examples are the effects of attention and alcohol consumption.

\section{Level 3 Effects}

Level 3 effects apply to all people, can be quantified, and can be specifically applied, at least to some degree, in a particular real-life situation. Examples include the effects of duration, lighting, and distance.

Level 3 effects can be used to infer genuine and potentially serious limitations in a witness's ability to accurately perceive and memorize relevant aspects of the scene. The following are three examples of how this might be done.

Duration calculations. Increasingly, crimes are recorded via closed-circuit television (CCTV). The usefulness of such recordings for actually identifying a perpetrator is limited because (1) recording quality is generally poor and (2) humans are not good at matching CCTV images to other photographs or to actual people (e.g., Bruce, Henderson, Newman, \& Burton, 2001). However, a CCTV recording can sometimes reveal the maximum time that a witness had to view a perpetrator. Combining such information with the well-known fact that eye fixations on a static scene can be made at a maximum rate of about $4 / \mathrm{sec}$ allows semiquantitative conclusions about how much of the scene the witness was able to visually process. In the extreme, for example, discovering that a witness had less than $0.25 \mathrm{sec}$ to perceive a perpetrator would indicate that the witness could have attended to, at most, only one part of the perpetrator's visual appearance.

Illumination calculations. In some instances, one can reliably determine how much light was available to the witness during a crime and, in particular, whether lighting was below scotopic levels. If so, one can be confident that no information about color was originally encoded, and one can make quantitative conclusions about the degree of perceptible detail.
Distance calculations. The best candidate for easily available quantitative calculations has to do with effects of information loss as a consequence of seeing a person (or an object) from some specified distance. I will spend the remainder of this section describing the logic underlying this assertion and providing four case-specific examples.

\section{Representing Distance by Blurring}

Intuitively, increasing distance diminishes one's ability to see progressively larger visual details. It is less intuitive that loss of information corresponding to a given distance is equivalent to blurring an object, such as a face, by a suitable amount. It is quite unintuitive that, on the basis of reasonable assumptions about visual information processing, amount of blur, suitably defined, is proportional to distance. Although a detailed explanation of this assertion is beyond the scope of this article, here, briefly, is why it is true.

Image representations and spatial filtering. A visual image can be represented in either pixel space (the usual way) or frequency space. In frequency space, an image is considered to be a weighted sum of two-dimensional sinewave gratings of all possible spatial frequencies and orientations that are allowable by the image's dimensions.

A spatial filter adjusts the distribution of weights corresponding to the various spatial frequencies that make up the image. Of relevance to this discussion is that a low-pass filter disproportionately decreases the weights of higher spatial frequencies - loosely speaking, fine detail — which is tantamount to blurring the image.

The human visual system, like any optical system, acts as a low-pass filter, which means, among other things, that it is incapable of seeing spatial frequencies higher than some maximum. For purposes of this discussion, I refer to this maximum as $F_{1}$, which is in units of cycles per degree of visual angle. There is an analogous image parameter, $f_{1}$, which is the image's highest perceivable spatial frequency in units of cycles/image.

There is a reciprocal relation between the distance between the image and the eye and $f_{1}$, the highest perceivable image spatial frequency; that is, $1 / f_{1}$ is proportional to distance. G. R. Loftus and Harley (2005) measured the proportionality constant, which, in turn, provides the information required to blur an image so that it mimics the information loss corresponding to a witness's seeing some object — such as a criminal's face - from any particular distance.

Application to legal cases. It is thus possible to show a jury such a blurred image to assist them in deciding whether a witness could have perceived what he or she claimed to have perceived. Some examples are the following.

1. Person perception. Figure 1A shows the representation of Darrell Edwards - the alleged New Jersey murderer described at the outset of this article - as seen from $271 \mathrm{ft}$, the distance of the eyewitness who subsequently identified him.

2. Car perception. In a California road rage case, the question arose as to whether a freeway driver could perceive whether another car one fourth of a mile ahead of 


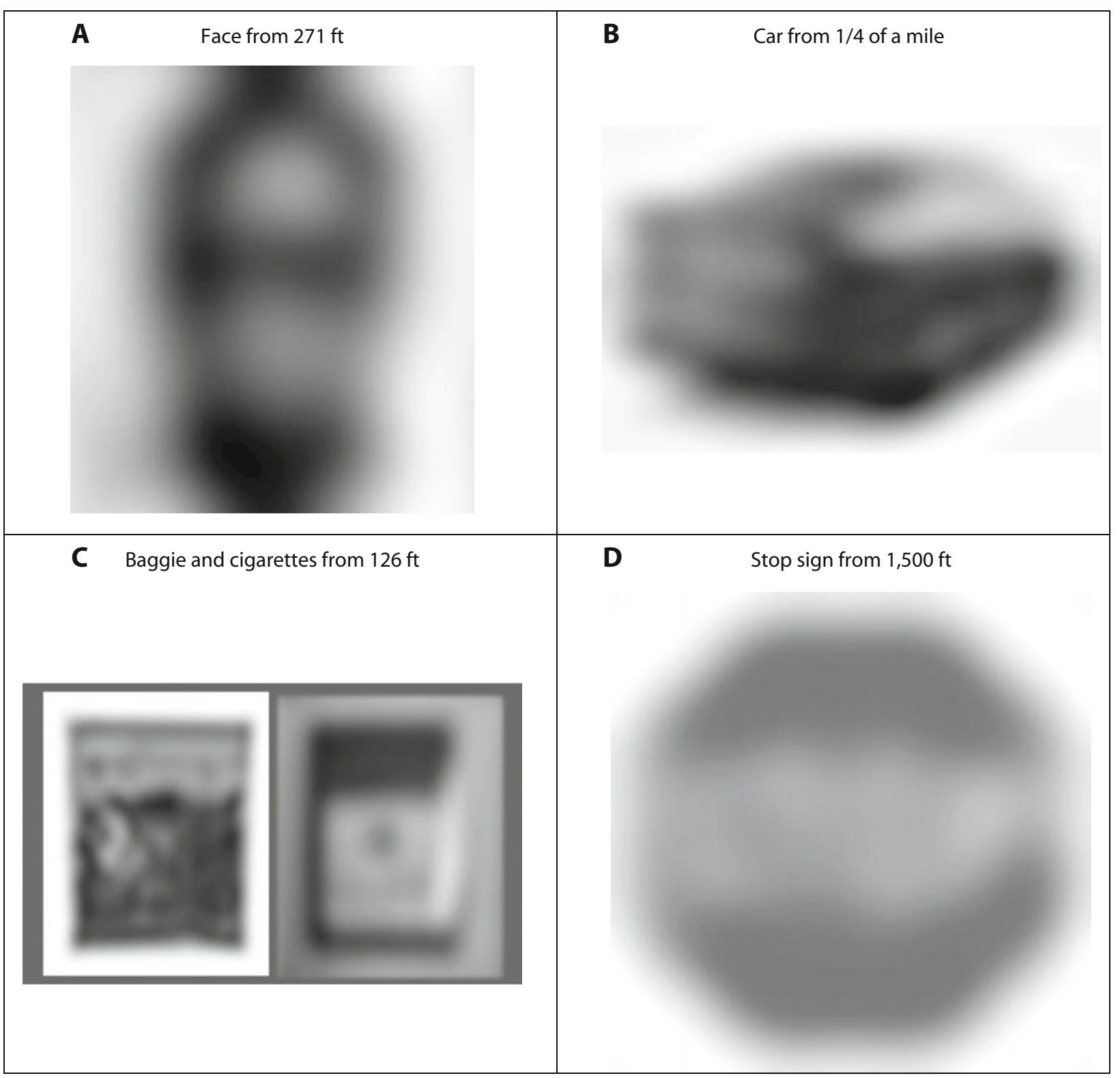

Figure 1. Objects of various sorts, blurred to represent distances.

him did or did not have a spoiler. Figure 1B shows a car as seen from this distance.

3. Marijuana baggie perception. In Montana, a middleschool boy was accused of holding a baggie of marijuana after having been viewed by a teacher from a distance of $126 \mathrm{ft}$. The boy claimed that he did not have a baggie of marijuana but, rather, had a pack of menthol cigarettes. Figure 1C shows the two objects in question as viewed from this distance.

4. Stop sign perception. A New Jersey state trooper, pursuing a speeder at night along a dark, semirural road, failed to see an obscured stop sign, which resulted in a fatal crash. The trooper, subsequently on trial for vehicular homicide, asserted in his defense that an unobscured stop sign 1,500 ft down the road captured his attention and was thus primarily responsible for his missing the relevant stop sign. A key question was, could the trooper have actually recognized from $1,500 \mathrm{ft}$ that the more distant stop sign was in fact a stop sign? Figure 1D shows how the stop sign would have appeared to him.

\section{SUMMARY}

A major task for perception-memory experts is to describe to a jury the conditions under which a witness's high confidence in some memory does not necessarily imply that the witness's memory is correct. In general, a necessary precursor for such conditions is that circumstances for original perception of the stimuli in question be poor. Thus, an eyewitness expert can describe why 
and when various perceptual factors contribute to such circumstances.

Such factors can be usefully categorized in terms of whether they can or cannot be unambiguously applied to a particular case. Three (somewhat subjective) categories consist of (1) factors that can be applied probabilistically and do not necessarily apply to all people (e.g., cross-racial identification and stress); (2) factors that can be applied probabilistically but do apply to all people (e.g., attention and alcohol consumption); and (3) factors that can be unambiguously and, to at least some degree, quantitatively applied to a particular witness in a particular situation (e.g., duration, lighting, and distance).

\section{AUTHOR NOTE}

This study was supported by NIMH Grant MH41637 to G.R.L. Correspondence concerning this article should be addressed to G. R. Loftus, Department of Psychology, University of Washington, Box 351525, Seattle, WA 98195-1525 (e-mail: gloftus@u.washington.edu).

\section{REFERENCES}

Artwohl, A. (2003). No recall of weapons discharge. Law Enforcement Executive Forum, 2, 41-49.

Bartlett, F. C. (1932). Remembering: A study in experimental and social psychology. Cambridge: Cambridge University Press.

Berkun, M. M., Bialek, H. M., Kern, R. P., \& Yagi, K. (1962). Experimental studies of psychological stress in man. Psychological Monographs: General \& Applied, 76(Whole No. 534).

Bruce, V., Henderson, Z., Newman, C., \& Burton, A. M. (2001). Matching identities of familiar and unfamiliar faces caught on CCTV images. Journal of Experimental Psychology: Applied, 7, 207-218.

CECI, S. J., \& BrucK, M. (1993). The suggestibility of the child witness: A historical review and synthesis. Psychological Bulletin, 113, 403-409.

LaUghery, K. R., AleXANDER, J. F., \& LANE, A. B. (1971). Recognition of human faces: Effects of target exposure time, target position, pose position, and type of photograph. Journal of Applied Psychology, 55, 477-483.
Levin, D. T., \& Simons, D. J. (1997). Failure to detect changes to attended objects in motion pictures. Psychonomic Bulletin \& Review, 4, 501-506.

Loftus, E. F. (2003). "Make-believe memories." American Psychologist, 58, 867-873.

Loftus, E. F., \& PAlmer, J. C. (1974). Reconstruction of automobile destruction: An example of the interaction between language and memory. Journal of Verbal Learning \& Verbal Behavior, 13, 585589.

Loftus, G. R., \& Harley, E. M. (2005). Why is it easier to recognize someone close than far away? Psychonomic Bulletin \& Review, 12, 43-65.

Meissner, C. A., \& Brigham, J. C. (2001). Thirty years of investigating the own-race bias in memory for faces: A meta-analytic review. Psychology, Public Policy, \& Law, 7, 3-35.

Penrod, S., \& Cutler, B. (1995). Witness confidence and witness accuracy: Assessing their forensic relation. Psychology, Public Policy, \& Law, 1, 817-845.

Quintyn, J. C., Massy, J., Quillard, M., \& Brasseur, G. (1999). Effects of low alcohol consumption on visual evoked potential, visual field and contrast sensitivity. Acta Ophthalmologica Scandinavica, 77, 23-26.

Steblay, N. M. (1992). A meta-analytic review of the weapon focus effect. Law \& Human Behavior, 16, 413-424.

Wells, G. L., \& Seelau, E. P. (1995). Eyewitness identification Psychological research and legal policy on lineups. Psychology, Public Policy, \& Law, 1, 765-791.

Yerkes, R. M., \& Dodson, J. D. (1908). The relation of strength of stimulation to rapidity of habit-formation. Journal of Comparative \& Neurological Psychology, 18, 459-482.

\section{NOTE}

1. Typically, although not always, a showup is carried out for reasons of expediency; following the crime, a suspect is quickly apprehended, and the witness is still present and available for an identification procedure. However, showup procedures can occur at any time; for instance, an in-court identification of a defendant by a witness is, for all intents and purposes, a showup procedure.

(Manuscript received June 17, 2009 revision accepted for publication October 10, 2009.) 